\title{
Role of Atlantic air-sea interaction in modulating the effect of Tibetan Plateau heating on the upstream climate over Afro-Eurasia-Atlantic regions
}

\author{
Mengmeng $\mathrm{Lu}^{1} \cdot$ Bohua Huang ${ }^{2} \cdot{\text { Zhenning } \mathrm{Li}^{1} \cdot \text { Song Yang }}^{1,3,4}$ - Ziqian Wang ${ }^{1,3,4}$
}

Received: 26 July 2018 / Accepted: 19 December 2018 / Published online: 31 December 2018

(c) The Author(s) 2018

\begin{abstract}
Previous studies have demonstrated that atmospheric diabatic heating over the Tibetan Plateau (TP) exerts significant influences on the "upstream" climate of the Atlantic-African-European sector in boreal summer. Using the NCAR Community Earth System Model, this study demonstrates that the TP-induced change in North Atlantic sea surface temperature (SST) including evident warming over the mid-latitude North Atlantic and cooling over the south can in turn modulate the above TP impact. Compared with the TP heating experiment without Atlantic SST variation, anomalous wave train pattern appears with north-northeastward downstream influences when the change in Atlantic SST is considered. The wave train pattern is characterized by three positive centers over the North Atlantic, the Arctic Ocean, and east of Japan, and four negative centers over northeastern North America, North Europe, the mid-Atlantic, and the northwestern Pacific. It intensifies the northern portions of the TP-induced tropospheric anticyclones over the extratropical North Atlantic and the cyclones over northeastern North America and North Europe. Correspondingly, precipitation decreases over the northwestern Atlantic but increases over northeastern North America and North Europe. Due to the easterly anomalies on the southern side of the weakened thermal low over subtropical Africa, precipitation over the Sahel decreases, indicating a weakening of TP-induced precipitation dipole over the tropical eastern Atlantic and West Africa when the Atlantic SST influence is considered. Overall, the modulation of Atlantic SST variation accounts for above 20 percent of the upstream climate signals induced by the TP thermal effect.
\end{abstract}

Keywords Atlantic sea surface temperature $\cdot$ Tibetan Plateau $\cdot$ Atmospheric teleconnection $\cdot$ Climate variations

\section{Introduction}

Zhenning Li

lzhenn@mail2.sysu.edu.cn

Song Yang

yangsong3@mail.sysu.edu.cn

1 School of Atmospheric Sciences, Sun Yat-sen University, 135 West Xingang Road, Guangzhou 510275, China

2 Department of Atmospheric, Oceanic, and Earth Sciences and Center for Ocean-Land-Atmosphere Studies, George Mason University, Fairfax, Virginia, USA

3 Guangdong Province Key Laboratory for Climate Change and Natural Disaster Studies, Sun Yat-sen University, Guangzhou, China

4 Southern Laboratory of Ocean Science and Engineering, Sun Yat-sen University, Zhuhai, China
The impacts of the Tibetan Plateau (TP) on regional and large-scale atmospheric circulation have been investigated extensively (Hahn and Manabe 1975; Ye and Wu 1998; Kitoh 2004; Liu et al. 2007; Wu et al. 2014). In particular, the importance of the TP thermodynamical effect has long been emphasized (Duan et al. 2008, 2017; Wang et al. 2008, 2014; Wu et al. 2012a, b; Rajagopalan and Molnar 2013; Liu et al. 2017), given that the large-scale orography is a huge heat source during the warm season (Koo and Yeh 1955; Flohn 1957; Yeh et al. 1957; Jiang et al. 2016). The effect of TP surface heating has also been studied comprehensively. For example, Ye and Wu (1998) indicated that the TP surface heating affected not only the local atmospheric circulation via strong convergence (divergence) and positive (negative) vorticity at the lower (upper) levels, referred to as the air pumping effect by Wu et al. $(1997,2007)$, but also the global general circulation through vertical cells and 
Rossby wave ray. Moreover, Nan et al. (2009) demonstrated that the springtime tropospheric temperature over TP played an important role in the subsequent variation of sea surface temperature (SST) over the tropical Pacific. Previous studies have also suggested that the increase in TP surface temperature further enhances the summer rainfall over East Asia on interdecadal time scales (e.g. Wang et al. 2008). Most of these studies have focused on the effect of TP on the climate over its "downstream" regions especially eastern Asia, referenced with respect to the direction of the prevailing westerly winds.

On the other hand, how the TP affects the climate over the "upstream" regions still remain unclear. In this context, limited studies have discussed the impacts of heating over Asia including the TP on the Mediterranean and Eurasian climate (Rodwell and Hoskins 1996; Wu et al. 2009). Zhao et al. (2012) also revealed that some North Atlantic climate anomalies originated from the Asian continent. Recently, Lu et al. (2018) conducted several sensitivity experiments using the NCAR Community Earth System Model with controlled modification of the surface thermal condition in the TP region and demonstrated the influences of summer TP heating on the "upstream" climate over the North Atlantic, South Europe, North Africa, the Middle East, and West Asia. In addition to the eastern Sahara and Mediterranean regions (e.g., Rodwell and Hoskins 1996, 2001), Lu et al. (2018) emphasized that the TP heating could lead to significant climate signals at the far western end in its sphere of influence. Specifically, the TP-related climate signals include intensification and northward shift of the subtropical high over the North Atlantic, especially in its northern flank near the Gulf Stream, and a northward shift of the intertropical convergence zone (ITCZ) which causes an increase in the Sahel rainfall. The former is due mainly to the TPheating induced Rossby wave response over the extratropics (effect on the rotational motion of the atmosphere) and to the thermally-driven atmospheric circulation over the tropics and subtropics (effect on the divergent flow).

It is interesting to note that these atmospheric responses are accompanied by coherent and significant SST signals in the North Atlantic, implying significant air-sea feedbacks initiated by the remote TP forcing. The influence of TP heating is indeed important, while its intensity and variation can also be modulated by remote oceanic forcing such as the SST variations over the North Atlantic (Cui et al. 2015) and the Indian Ocean (Zhao et al. 2018; Wang et al. 2018). In addition, the variations of Atlantic SST exert strong impacts on regional and global climate (Xie and Carton 2004; Hurrell et al. 2006; Luo et al. 2011; Li and Ruan 2018). On interannual time scales, the warm SST anomalies in the eastern equatorial Atlantic peaking in boreal summer (the Atlantic Niño; Carton and Huang 1994) usually lead to a southward shift of the ITCZ. These anomalies in the cold tongue-ITCZ complex generate drier condition over the Sahel region (Horel et al. 1986; Fontaine and Janicot 1996; Ward 1998) but wet conditions in the Gulf of Guinea and Angola coast (e.g., Wagner and da Silva 1994). Further to the north, summer SST anomalies are dominated by the North Atlantic horseshoe (NAH) pattern, with one branch near Newfoundland wrapped around by the other branch of opposite sign extending from Ireland to Morocco coast (Czaja and Frankignoul 2002). The latter branch also extends into the northern tropical Atlantic (Huang and Shukla 2005). The NAH pattern is a seasonal manifestation of the Atlantic Multidecadal Oscillation (AMO) and significantly influences the summer climate over North America and Europe (Sutton and Hodson 2005). On interdecadal time scale, the cold phase of AMO is responsible for the decreased rainfall over the Sahel (Rodriguez-Fonseca et al. 2015). Both the Atlantic Niño and the AMO influence the Indian monsoon through teleconnection patterns (Kucharski et al. 2009; Lu et al. 2006).

Observationally, many Atlantic SST anomalies are remotely forced by global climate variations such as El Niño-Southern Oscillation (ENSO) and the North Atlantic Oscillation (NAO) (e.g., Czeja et al. 2002; Huang 2004). On the other hand, these originally-forced SST signals can feedback actively onto the atmospheric circulation and influence regional climate. It is noticeable that both ENSO and NAO influence the Atlantic Ocean most strongly during boreal winter-spring (e.g., Yang et al. 2017) and previous studies have concentrated on the Atlantic SST influences in the cold season (e.g., Sun et al. 2017). However, the influences of the Atlantic SST changes induced by the major summer climate phenomena (e.g., the Asian summer monsoon) on the regional atmospheric circulation have yet to be understood. As discussed above, Lu et al. (2018) explored significant TP-related changes in the climate to the west of the plateau, including the anomalies of SST and geopotential height over the North Atlantic. The study was perhaps among the first in deliberately revealing the effect of TP on the upstream climate to its west. However, the analysis left an important issue unaddressed: the effect of Atlantic ocean-atmosphere interaction on the upstream atmospheric response to TP heating. What are the physical processes related to the Atlantic SST variation being revealed? To what extent do the TPinduced Atlantic SST signals feedback onto the atmospheric circulation and surface climate anomalies directly forced by the TP heating? Here we conduct this analysis with a clear purpose: to understand the patterns and mechanisms for the possible role of the variation of Atlantic SST in modulating the effect of TP on the Afro-Eurasia-Atlantic climate.

This paper is organized as follows. The global model and experiment design are introduced in Sect. 2. In Sect. 3, the role of Atlantic SST in modulating the effect of TP heating on upstream climate and related physical processes are 
discussed. Finally, conclusions and a further discussion are provided in Sect. 4.

\section{Model and experiment design}

\subsection{Model}

Version 1.2.2 of the NCAR Community Earth System Model is applied in this study. The state-of-the-art general circulation model is fully coupled, with interacting components of the atmosphere (CAM4), ocean (POP2), land (CLM4), and sea ice (CICE4) (Hurrell et al. 2013). The coupled system is configured globally with the atmospheric component having a $1.9^{\circ} \times 2.5^{\circ}$ horizontal resolution and 26 vertical levels. The global ocean model is at an approximate $1^{\circ}$ horizontal resolution on a tripolar coordination and 60 levels. All model simulations are conducted with the B2000 component setting; that is, the values of solar forcing, carbon dioxide, aerosol, and ozone concentration are fixed at their levels of Year 2000.

\subsection{Experiment design}

A fully-coupled integration with 300 years is performed as the control run (CON). To understand the effect of TP heating on the upstream climate and the possible role of Atlantic SST in this impacting process, two sensitivity experiments are conducted. One is the same run (TP_Alb0.5) as reported in Lu et al. (2018), which restarts from year 251 of CON and continues to be integrated for 50 years with half of the original surface albedo over $23^{\circ} \mathrm{N}-45^{\circ} \mathrm{N} / 62^{\circ} \mathrm{E}-105^{\circ} \mathrm{E}$ where the TP elevation is above $1500 \mathrm{~m}$, from May to September. The enhancement of surface sensible heat flux with the reduced surface albedo over the TP is basically comparable to the observed change in the last 30 years reported by Duan et al. (2011), which will serve as a main thermal forcing on the atmosphere. The other experiment (TP_noAtlantic) is the same as the TP_Alb0.5 except that the Atlantic domain over $22^{\circ} \mathrm{S}-60^{\circ} \mathrm{N}$ is uncoupled (Fig. 1, red regions). Technically, we replace the first-layer (10-m depth) temperature of the ocean model with the climatological annual cycle of the first-layer ocean temperature derived from CON. As a result, the atmosphere "sees" a prescribed annual cycle of the SST in this area. The Atlantic domain is chosen because significant changes in SST appear over the Gulf of Guinea and the subtropical-extratropical Atlantic as shown in TP Alb0.5 (see Lu et al. 2018), and because the air-sea interaction over these regions plays an important role in affecting the surrounding climate (Huang et al. 2004; Xie and Carton 2004; Hurrel et al. 2006). The outputs of the last 40 years from all experiments are analyzed and the differences in SST and atmospheric patterns between the two sensitivity

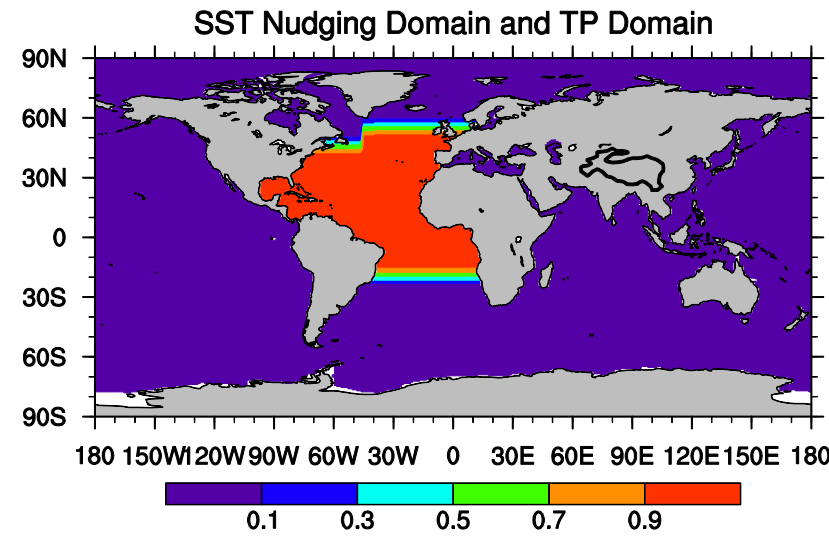

Fig. 1 Domains of nudging SST (shadings) and TP forcing (contour). The shadings indicate the nudging coefficients. The uncoupled region is in red and the coupled region in purple. The belts over the North Atlantic and the South Atlantic with varying colors are the blending zones

experiments are compared and contrasted to understand the modulation of Atlantic SST especially its feedback on the climate effect of TP heating.

\section{Results}

\subsection{Modulation of Atlantic SST on TP-induced surface climate anomalies}

In this section, we examine the modulation of Atlantic SST variation on the effect of TP heating on the upstream climate over Afro-Eurasia-Atlantic regions. Figure 2 shows the JJA climatological surface temperature and precipitation in $\mathrm{CON}$ (Fig. 2a, b), the corresponding changes of experiment TP_Alb0.5 (Fig. 2c, d) and experiment TP_noAtlantic from CON (Fig. 2e, f), as well as the differences between TP_Alb0.5 and TP_noAtlantic (Fig. 2g, h). Significant features of the summer climatology of surface temperature in the Atlantic sector and its surrounding continents include a warm zone in the subtropics centered at $30^{\circ} \mathrm{N}$, with significantly hotter land temperatures over southwestern US, North Africa, and the Middle East (Fig. 2a). Over the North Atlantic, surface temperature shows a typical "warm west - cool east" pattern, associated with a northward warm water transport by the Gulf Stream and a cool eastern boundary current and coastal upwelling near the Africa coast. Major precipitation features (Fig. 2b) include a rain belt over the Gulf Stream and its extension from Florida to the Grand banks of Newfoundland and the ITCZ located around $5^{\circ}-10^{\circ} \mathrm{N}$ across the Atlantic (Feng et al. 2017). In the east, this rain belt penetrates deeply into the continent, forming the West African monsoon. It should be pointed out that both rain belts are associated with high regional SSTs and large SST gradients 

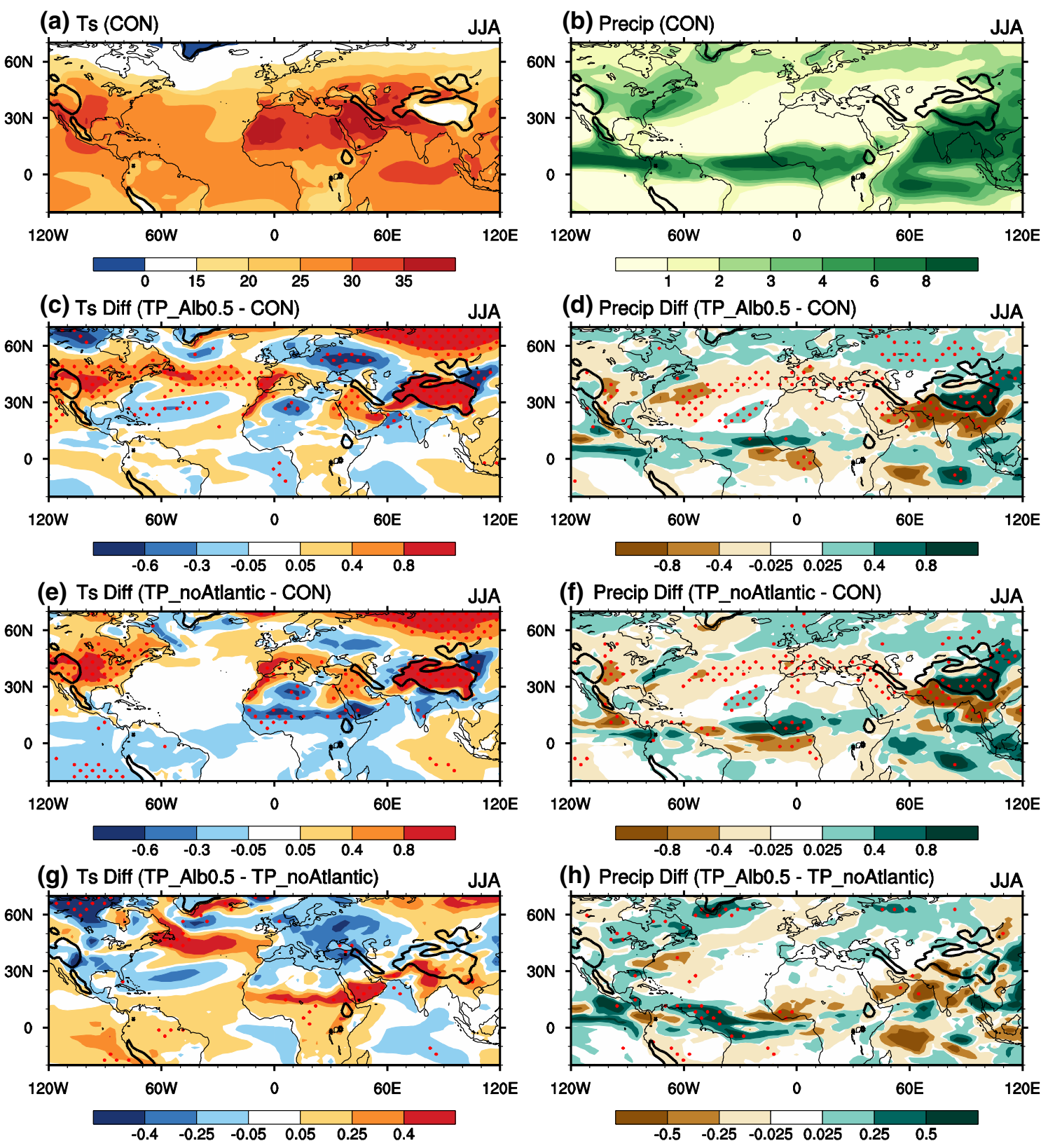

Fig. 2 JJA climatology of a surface temperature (units: ${ }^{\circ} \mathrm{C}$ ) and b precipitation (units: $\mathrm{mm} \mathrm{day}^{-1}$ ) in CON. Differences in c surface temperature and $\mathbf{d}$ precipitation between TP_Alb0.5 and CON; and differences in $\mathbf{e}$ surface temperature and $\mathbf{f}$ precipitation between $\mathrm{TP}_{-}$

in the Gulf Stream for the former and the equatorial cold tongue for the latter. These oceanic fronts do not appear clearly in Fig. 2a due to the large shading intervals.

In the TP_Alb0.5 run, surface temperature increases over the TP, the Middle East, and South Europe, but decreases over central Europe in the extratropics and India, the Arabian Sea, and northwestern Africa in the subtropics (Fig. 2c). Significant changes in surface temperature also appear over the North Atlantic and the Gulf of Guinea, with
noAtlantic and CON. g Difference between $\mathbf{c}$ and $\mathbf{e}$; and $\mathbf{h}$ difference between $\mathbf{d}$ and $\mathbf{f}$. Red dots indicate the significant values above the $90 \%$ confidence level. The topography above $1500 \mathrm{~m}$ is marked with thick black lines

a significant warming center over $45^{\circ} \mathrm{N}$ and a cooling center over $25^{\circ} \mathrm{N}$. The warming is caused by the decrease in cloud cover associated with reduced rainfall and increased surface net solar radiation, which is related to the intensified and northward shifted Atlantic subtropical high (ASH) induced by the TP thermal forcing. The cooling is induced by the enhanced trade wind and thus evaporation. These features have been discussed and referred to as the TP's effect in $\mathrm{Lu}$ et al. (2018). 
As seen from Fig. 2e, which shows the difference between TP_noAtlantic and CON, when the North Atlantic SST is fixed to its climatological annual cycle, the difference in surface temperature over the Atlantic is negligible as expected. Over the other regions, the overall temperature pattern is similar to that in TP_Alb0.5, although cooling is more (less) significant over subtropical Africa (western-central Europe). The difference in surface temperature between TP_Alb0.5 and TP_noAtlantic (former minus latter; Fig. 2g), which represents the Atlantic SST forcing in our model experiments, depicts a "positive-negative-positive-negative" structure of the Atlantic SST that reflects a strengthened meridional temperature gradient in the tropical-subtropical North Atlantic and a weakened meridional temperature gradient in the midlatitude North Atlantic (figure not shown). The patterns of surface heat fluxes are similar to the SST pattern (figures not shown). Positive (negative) surface heat flux occurs over the warming (cooling) region, meaning that more (less) energy is transported from oceans to the atmosphere. This feature indicates that the changes in meridional temperature gradients are expected to affect the atmospheric circulation and surface climate and thus modulate the climate effect of the TP through changing surface heat fluxes, which is the focus of this analysis. Also interesting is the change in the temperatures over land. The anomalous Atlantic SST pattern makes Europe and North America cooler by -0.25 and $-0.4{ }^{\circ} \mathrm{C}$, respectively, but subtropical North Africa and the southern Middle East warmer with maximum values above $0.4{ }^{\circ} \mathrm{C}$ (Fig. 2g).

As discussed previously, when the TP heating intensifies, precipitation increases over the TP but decreases over the regions to the south and the west of TP including northern India, the Middle East, the Mediterranean Sea, and the midlatitude North Atlantic (Fig. 2d). Especially, the reduced precipitation over the western Atlantic near $30^{\circ} \mathrm{N}$ together with the enhanced precipitation near the North America coast suggests a tightening of the rain belt toward the North America coast over the Gulf Stream. In addition, there exists a rainfall dipole over the tropical eastern Atlantic and West Africa, signifying a northward shift of the ITCZ. Compared to this precipitation pattern produced by the strengthened TP heating with Atlantic air-sea coupling, the precipitation distribution in TP_noAtlantic (Fig. 2f) is similar but the magnitude changes to various extents, revealing the contribution of the Atlantic air-sea feedback onto the precipitation variation. As seen from the difference in precipitation between TP_Alb0.5 and TP_noAtlantic (Fig. 2h), negative values appear over the western North Atlantic but positive values occur near the North America coast and over North Europe, with central values about -0.25 and $0.25 \mathrm{~mm} \mathrm{day}^{-1}$. This feature suggests that the air-sea feedback associated with the strong SST changes in the North Atlantic enhances the tightening of the regional rain belt. Associated with the slight increase in precipitation over North America and Europe, surface temperature decreases accordingly.

On the other hand, positive rainfall difference (Fig. 2h) appears over the slightly warmer SST in the equatorial western Atlantic in TP_Alb0.5 (Fig. 2g). It is noteworthy that, without air-sea feedback, precipitation decreases in TP_noAtlantic compared to the control run (Fig. 2f). Furthermore, precipitation decreases over the Sahel region with a value about $-0.5 \mathrm{~mm}^{\text {day }}{ }^{-1}$ but slightly increases over the south (Fig. 2h), indicating a weakening of the TP-induced precipitation dipole shown in Fig. 2f by the Atlantic SST. Indeed, the narrow band of strong warming over subtropical Africa (Fig. 2g) well corresponds to the negative center of this precipitation dipole, signifying a slight southward retreat of the ITCZ in TP_Alb0.5 compared to that in TP_noAtlantic. These results suggest that the Atlantic air-sea feedback tends to damp the TP-induced precipitation changes in the equatorial Atlantic and West Africa. Since the slight cooling in the Gulf of Guinea should favor a northward shift of the ITCZ, we conclude that the regional cooling does not induce the precipitation dipole in Fig. $2 \mathrm{~h}$. The reduced Sahel rainfall corresponds to the easterly anomalies on the southern side of the weakened thermal low over subtropical Africa, which weaken the water vapor transport from the tropical Atlantic to the Sahel.

\subsection{Modulation of Atlantic air-sea feedback on TP-induced atmospheric anomalies}

The evident changes in surface climate over the Atlantic and its surrounding regions discussed above are related to the variations of atmospheric circulation at various levels as shown in Figs. 3 and 4. In the lower troposphere, anomalous cyclonic circulation forms over nearly the entire Asian continent but anticyclonic anomalies appear over the mid-latitude Atlantic and Pacific when a heating is added to the TP (Fig. 3b), indicating the intensifications of the climatological Asian low, the northern portion of the ASH, and the western portion of the North Pacific anticyclone (refer to Fig. 3a). Climatologically, a lowlevel thermal low exists over subtropical Africa (Fig. 3a), whose strengthening enhances the Sahel summer rainfall through an increase in water vapor transport from the tropical Atlantic (Vizy and Cook 2017). In Fig. 3b, cyclonic anomalies, which are associated with the northward shift in the center of the subtropical high, occur over the southeast of the anticyclonic circulation over the Atlantic and subtropical Africa, implying that the water vapor transport from the tropical Atlantic to the West African monsoon region can be enhanced due to the intensified heat low and associated westerly anomalies over tropical Africa. The above features can also be seen when the effect of Atlantic air-sea feedback is excluded (Fig. 3c); however, 
Fig. 3 Sea level pressure (shadings, units: hPa) and 850-hPa winds (vectors, units: $\mathrm{m} \mathrm{s}^{-1}$ ): a JJA climatology of CON, b difference between TP_Alb0.5 and CON, $\mathbf{c}$ difference between TP_noAtlantic and CON, and $\mathbf{d}$ difference between $\mathbf{b}$ and $\mathbf{c}$. Red dots indicate the significant values above the $90 \%$ confidence level. For wind difference, only the significant values above the $90 \%$ confidence level are plotted. The topography above $1500 \mathrm{~m}$ is marked with thick black lines

\section{(a) SLP \& UV850 (CON)}

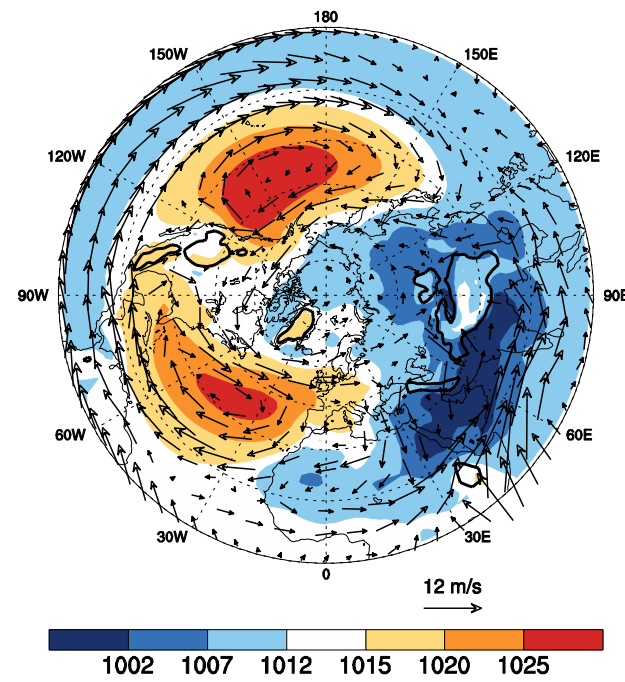

(c) SLP \& UV850 Diffs (TP_noAtlantic - CON)

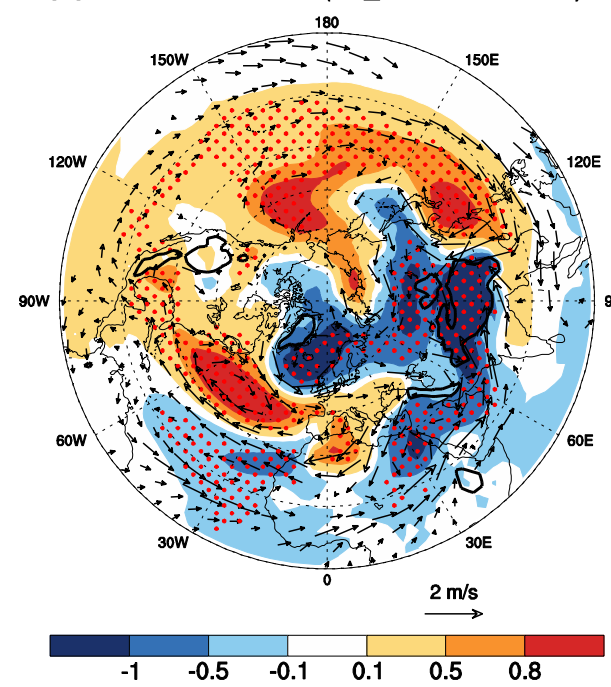

(b) SLP \& UV850 Diffs (TP_Alb0.5 - CON)

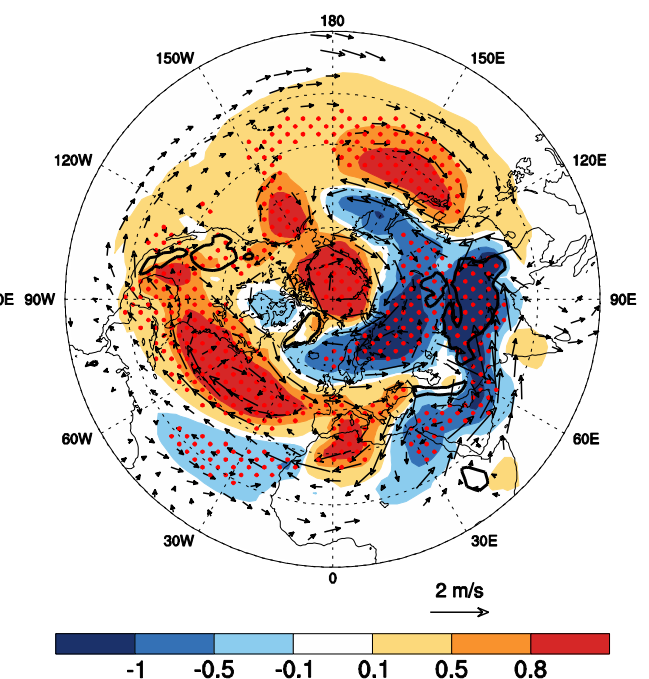

(d) SLP \& UV850 Diffs (TP_Alb0.5 - TP_noAtlantic)

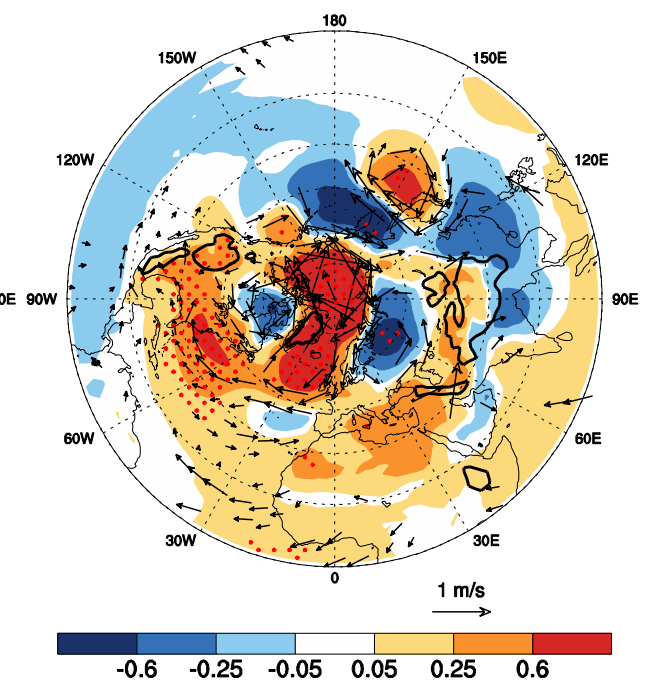

its anticyclonic circulation over the mid-latitude Atlantic is weaker and the cyclonic anomalies to the south and the heat low over subtropical Africa are stronger than their counterparts in TP_Alb0.5. The difference in the lower tropospheric circulation between TP_Alb0.5 and TP_ noAtlantic further shows that the Atlantic air-sea feedback enhances the anticylonic circulation over the western Atlantic around $40^{\circ} \mathrm{N}$, partially as a response to the heat sources associated with the changes in the Gulf Stream rain belt. The atmospheric perturbation then disperses as the stationary Rossby wave that branch out further downstream to two tracks, one toward Europe and the other toward the North Pole (Fig. 3d). In particular, the former generates the anticyclonic circulation in northeastern Atlantic and the cyclonic circulations over northeastern North America and northern Europe, causing increased precipitation and decreased surface temperature over the regions.

The Atlantic atmospheric signals may be partially explainable as the direct response to the change in the underlying SST. For instance, the warm SST belt at around $45^{\circ} \mathrm{N}$ and the cold SST belt near $25^{\circ} \mathrm{N}$ reduce the meridional air temperature gradient (Fig. $2 \mathrm{~g}$ ) and enhance easterly anomaly according to the principle of thermal wind balance (Fig. 3d) (e.g., Lindzen and Nigam 1987). Superimposed on the background surface wind, this wind anomaly tends to strengthen the existing SST pattern. This positive feedback over the northern subtropical Atlantic favors high pressures over the North Atlantic and weak cyclonic anomalies appear around $40^{\circ} \mathrm{N} / 30^{\circ} \mathrm{W}$. These changes cause a further strengthening of the anticyclonic circulation over the mid-latitude Atlantic and a weakening of the cyclonic circulation to the 
Fig. 4 Same as Fig. 3, but for 500-hPa geopotential height (shadings, units: $\mathrm{m}$ ), 200-hPa geopotential height (contours, units: $\mathrm{m}$ ), and 200-hPa winds (vectors, units: $\mathrm{m} \mathrm{s}^{-1}$ ) (a) H50O, H200, UV200 (CON)

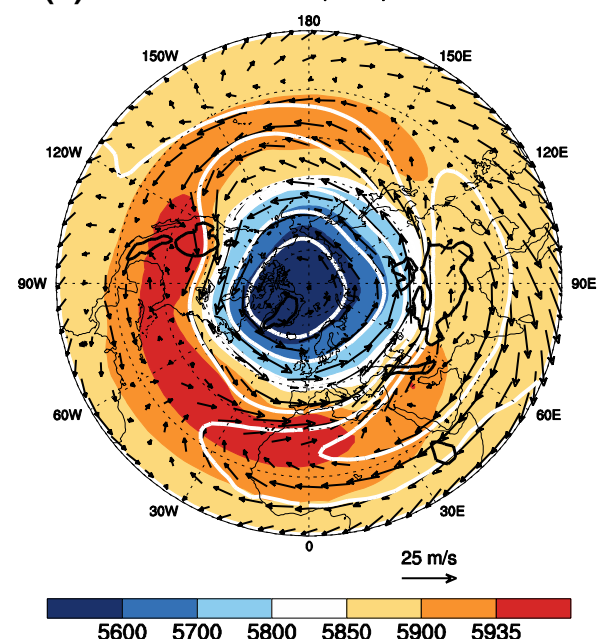

(c) H500, H200, UV200 Diffs (TP_noAtlantic - CON)

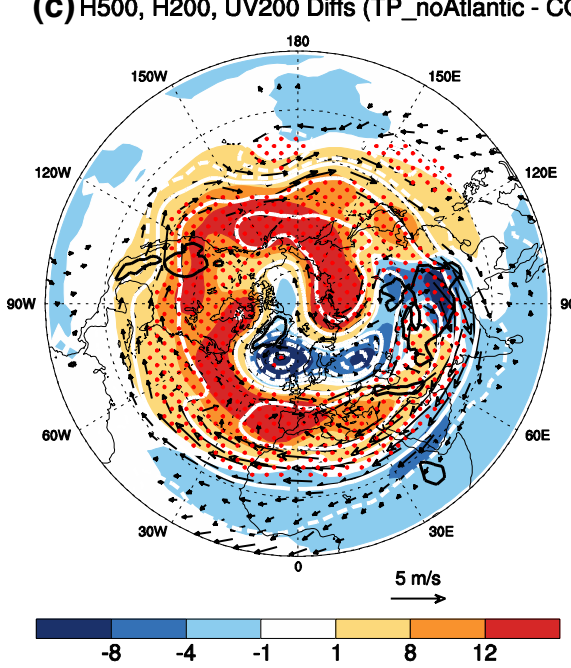

(b) H500, H200, UV200 Diffs (TP_Alb0.5 - CON)

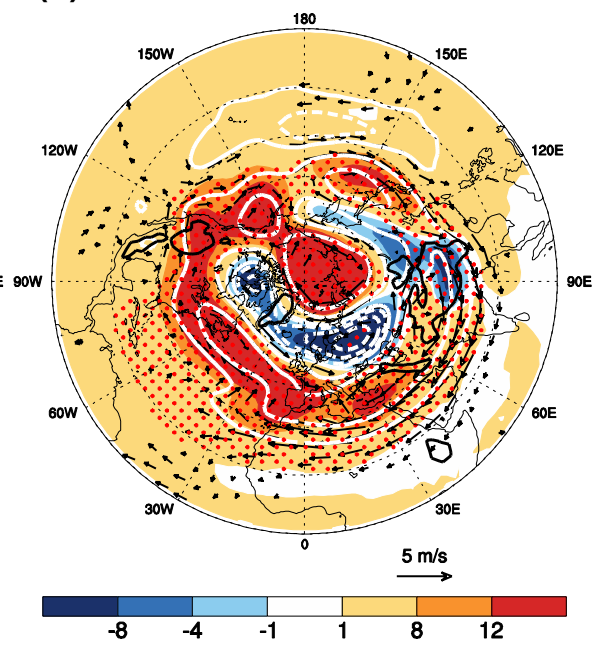

(d) H500, H200, UV200 Diffs (TP_Alb0.5 - TP_noAtlantic)

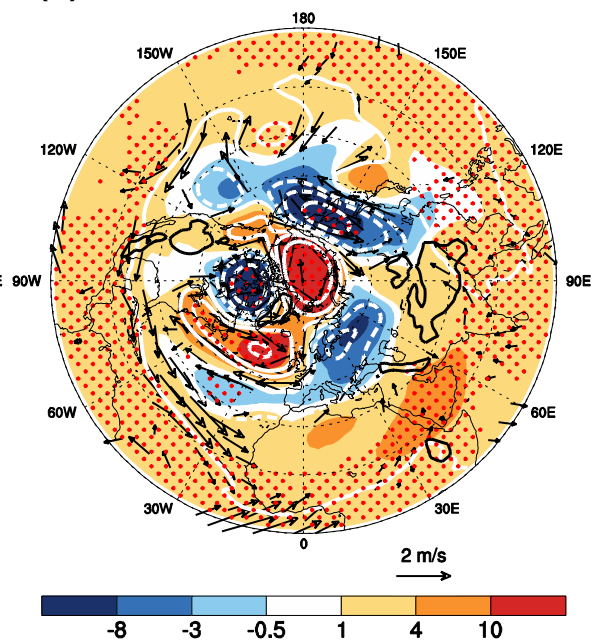

south in TP_Alb0.5 (Fig. 3b) compared to TP_noAtlantic (Fig. 3c). Correspondingly, significant negative anomalies of precipitation occur over the mid-latitude western Atlantic (Fig. 2h). Moreover, the North Atlantic high-pressure system in TP_Alb0.5 extends strongly on both east and west ends into the continents (Fig. 3b). In particular, the anticyclonic ridge over northern Africa near the Greenwich longitude seems to block the further westward extension of low pressure related to TP heating and thus weakens the heat low over subtropical Africa. Over the tropical Atlantic, the convergence in the east and the divergence to the west are weakened due to the easterly anomalies to the south of the anomalous anticyclonic circulation, implying a weakened heat low. Therefore, a west-east dipole pattern of precipitation forms over the tropical Atlantic (Fig. 2h).

In the middle troposphere, a wave-like response to enhanced TP heating occurs over the mid-high latitudes of the Northern Hemisphere, with positive centers over the Arctic Ocean, east of Japan, and regions from mid-latitude
North America to the Mediterranean Sea, but negative centers over the main body of TP, North Europe, and northeastern North America (shadings in Fig. 4b). The high-level atmospheric response is similar to that in the middle level (contours and vectors in Fig. 4b), except for the opposite signals over the mid-upper troposphere of the TP. Correspondingly, the northern part of the ASH intensifies and its center moves northward compared to its climatology shown in Fig. 4a. When the effect of Atlantic SST is removed, the main features of atmospheric responses are similar but the negative center over North Europe weakens and that over northeastern North America moves eastward to the southeast of Greenland (Fig. 4c).

The Rossby wave structure related to the effect of Atlantic air-sea coupled feedback can be seen more clearly in the middle and upper levels, with three positive centers over the northern Atlantic, the Arctic Ocean, and east of Japan and four negative centers over northeastern North America, North Europe, the mid-Atlantic, and the northwestern Pacific 
(Fig. 4d). The pattern is similar to that in the lower level (Fig. 3d), indicating an equivalent barotropic structure in the troposphere. However, the wave path in Fig. 4d is more pronounced along a north-south direction, which is consistent with the linear model response of the upper atmosphere to a mid-latitude heat source at $46^{\circ} \mathrm{N}$ by Hendon and Hartmann (1982) (their Fig. 6), who also noticed that the surface heat flux feedback played a significant role in determining the wave response. An analysis of the relevant difference patterns for stream function perturbation and wave activity flux (WAF, Plumb 1985; figures not shown) reveals consistent features to those shown in Fig. 4. WAF propagates northward from the extratropical North Atlantic to the North Pole around $60^{\circ} \mathrm{W}$, indicating a dominant source of WAF. However, the WAF over Europe is not very clear and only limited eastward-propagating WAF can be seen.

Visually, our lower-atmospheric response seems to be more zonal and its downstream propagation effectively modulates the upstream influence of the TP heating. The features of temperature and precipitation corresponding to these changes in atmospheric circulation are also evident (Fig. 2g, h). In particular, negative rainfall anomalies occur over the northwestern Atlantic but positive rainfall and negative temperature anomalies appear over North Europe and northeastern North America. The two anomalous pressure centers over the extratropical North Atlantic indicate strengthening of the northern part and weakening of the southern part of the anticyclonic anomalies induced by TP heating.

\subsection{Quantitative depiction of the role of Atlantic SST in the climate impact of TP}

We further define [(TP_Alb0.5 - CON $)$ - (TP_noAtlantic - CON)]/(TP_Alb0.5 - CON), i.e. ratios for atmospheric circulation and surface climate variables as shown in Figs. 5 and 6, to reveal the importance of Atlantic SST variation for the climate effect of TP heating on the upstream climate quantitatively. To consider the common features and impacts of enhanced TP heating in the experiments with and without Atlantic SST variation, only the areas where the values of both (TP_Alb0.5 - CON) and (TP_noAtlantic - CON) are of the same sign are considered in the figure. In addition, negative values are replaced by their absolute values, and the ratios are removed when the values of (TP_Alb0.5 - CON) are negligible. Therefore, the positive (negative) values represent enhancing (weakening) contribution of Atlantic air-sea feedback onto the effect of TP heating. Clearly, from the perspective of low-level atmospheric circulation, the main contribution of Atlantic SST variation to the TP effect occurs over the mid-latitude North American-Atlantic-European regions with positive values over the mid-Atlantic and a small negative center surrounded by the positive values (Fig. 5a). For the mid-upper troposphere, the ratio patterns
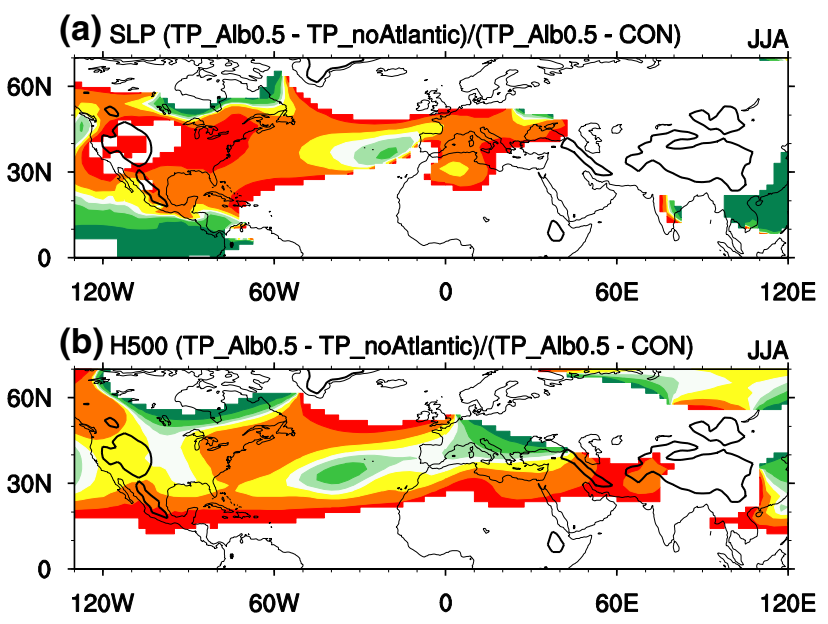

(c) H200 (TP_Alb0.5 - TP_noAtlantic)/(TP_Alb0.5 - CON) JJA

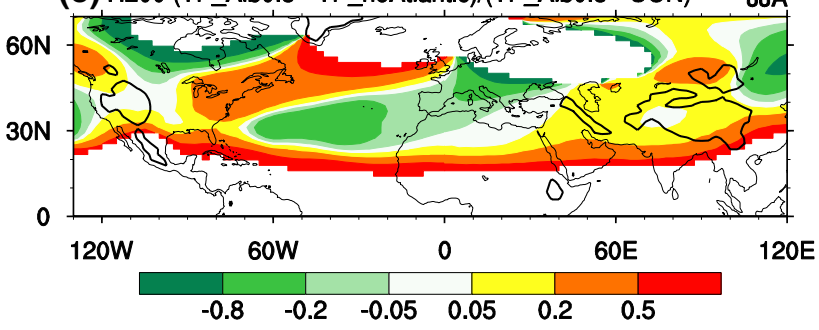

Fig. 5 Ratios of JJA a sea level pressure, b 500-hPa geopotential height, and c 200-hPa geopotential height, which are calculated as [(TP_Alb0.5 - CON) - (TP_noAtlantic - CON)]/(TP_Alb0.5 - CON). Only the regions where the values of both (TP_Alb0.5 CON) and (TP_noAtlantic - CON) are mutually positive or negative are plotted. Negative values are replaced by their absolute values. The ratios are not considered when the values of (TP_Alb0.5 - CON) are equal to zero

(a) Ts (TP_Alb0.5 - TP_noAtlantic)/(TP_Alb0.5 - CON)

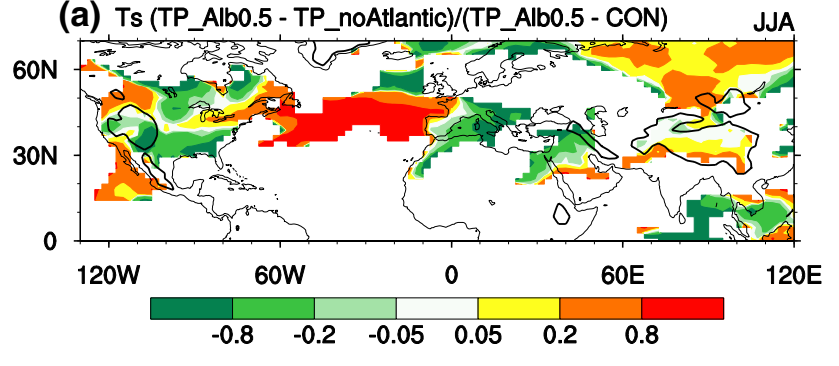

(b) Precip (TP_Alb0.5 - TP_noAtlantic)/(TP_Alb0.5 - CON)

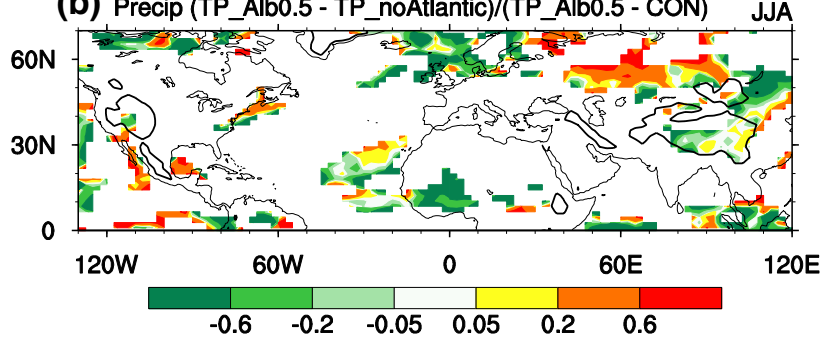

Fig. 6 Same as Fig. 5, but for ratios of JJA a surface temperature and b precipitation 
are similar to the pattern of low-level circulation, but another negative center appears over South Europe and the positive values extend eastward to the TP (Fig. 5b, c). The ratios over the North Atlantic imply an enhancement of the northern part and a weakening of the southern part of the anticyclonic anomalies over the extratropical North Atlantic, which is consistent with the result shown before. An examination of the magnitude of Atlantic SST impact indicates that most of the ratios are greater than $20 \%$, quantifying the contribution of Atlantic SST variation to the TP thermal impact on upstream climate discussed by Lu et al. (2018).

The ratios for surface temperature (Fig. 6a) reflect a moderating influence of Atlantic air-sea feedback on the temperatures over the Mediterranean Sea region and North America, which reconfirms the features shown above. It is reasonable that large positive values appear in the extratropical North Atlantic because of the design of our sensitivity experiments. The ratios for precipitation are negative over the Sahel, which indicates a negative contribution of Atlantic SST variation (Fig. 6b), consistent with the change in Sahel precipitation illustrated before.

\section{Conclusions and discussion}

Previous studies have shown that TP summertime heating can affect the "upstream" climate over the Atlantic-African-European regions. Given the significant changes in the Atlantic SST induced by the TP forcing and the importance of Atlantic SST anomalies for climate variations, in this study we demonstrate the modulation of this TP heating effect by Atlantic air-sea feedback and explore the physical processes involved using a fully-coupled earth system model. Compared with the TP heating experiment without the effect of Atlantic SST, experiment with Atlantic SST variation, which is characterized by an evident warming over the mid-latitude North Atlantic and a cooling over the south, produces significant climate signals in both tropical and extratropical Atlantic and the surrounding regions.

The main features of the modulation of TP climate impact by Atlantic SST variation can be summarized by the schematic diagram shown in Fig. 7. When the air-sea coupling in the Atlantic is active, the change in the North Atlantic SST can influence the meridional temperature gradient through the change in surface heat fluxes: enhancing the TP-induced anticyclonic anomalies over the mid-latitude Atlantic and weakening the cyclonic anomalies to the south. Correspondingly, negative anomalies of precipitation occur over the mid-latitude western Atlantic, which are associated with anomalous Rossby wave in the mid-high latitudes of the Northern Hemisphere with three positive centers over the North Atlantic, the Arctic Ocean, and east of Japan and four negative centers over northeastern North America, North

\section{(a) TP Heating with Atlantic SST Variation}

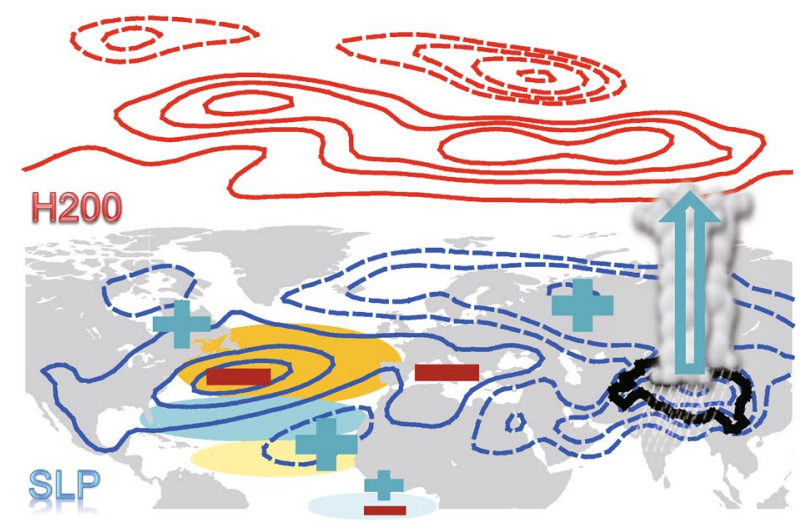

(b) TP Heating without Atlantic SST Variation

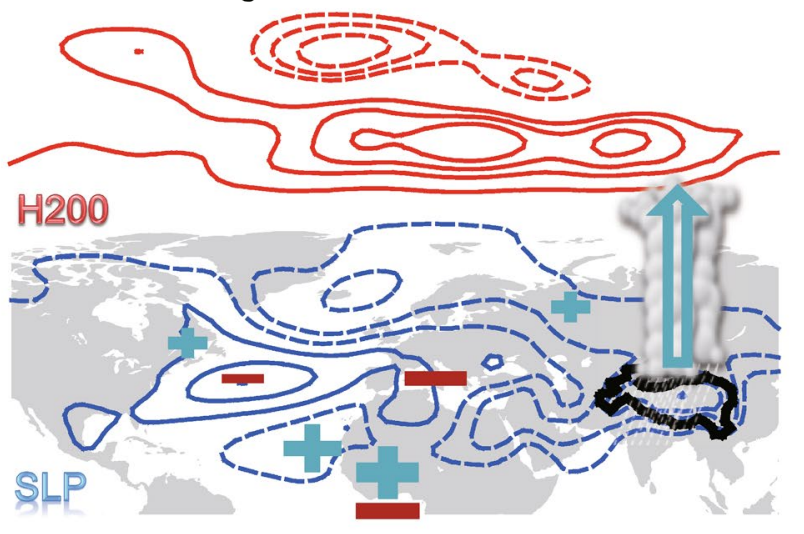

Fig. 7 Schematic diagram of the role of Atlantic SST change in the impact of TP heating on the upstream climate. a Atmospheric responses (red contours: 200-hPa geopotential height; blue contours: sea level pressure) to the TP heating with Atlantic air-sea interaction. b Those without Atlantic air-sea interaction. Solid contours indicate the anticyclonic anomalies, and dashed contours indicate the cyclonic anomalies. Orange and yellow ovals represent strong and weak warming over the extratropical and subtropical North Atlantic. Dark and slight blue ovals represent corresponding cooling over the mid-Atlantic and the Gulf of Guinea. Blue plus sign indicates anomalous rising motion and increased rainfall. Red minus sign indicates anomalous sinking motion and reduced rainfall. The larger the sign size, the larger the climate variables

Europe, the mid-Atlantic, and the northwestern Pacific. Corresponding to the negative centers of this wave train, positive rainfall and negative temperature anomalies over North Europe and northeastern North America induced by TP heating are enhanced.

The Atlantic SST pattern also decreases the precipitation over the Sahel due to the easterly wind anomalies associated with the weakened heat low over subtropical Africa, which weaken the water vapor transport from the tropical Atlantic to the Sahel. Corresponding to the decreased precipitation, surface temperature increases. These features indicate that the Atlantic SST variation 
weakens the TP-induced rainfall dipole over the tropical eastern Atlantic and West Africa.

Over the Atlantic and its surrounding regions, the degree of modification by the Atlantic SST on the effect of TP heating on atmospheric circulation are similar at various levels, explaining generally above $20 \%$ of the TP effect. That is, the Atlantic SST variation contributes an important portion to the impact of TP heating on the upstream climate.

Previous studies have shown that the SST anomalies over the Gulf of Guinea influence the West African and Indian summer monsoons significantly (Kucharski et al. 2009; Rodriguez-Fonseca et al. 2015). In particular, cold (warm) tropical Atlantic SSTs lead to increased (reduced) rainfall over West Africa and India. However, in our study, the precipitation over West Africa and India decreases when a slight cooling over the Gulf of Guinea is considered. This feature indicates that the rainfall variability over West Africa and India is modulated by the extratropical Atlantic SST anomalies that induce low-level circulation anomalies rather than the cooling over the Gulf of Guinea, which is probably too weak.

It should be pointed out that the Atlantic SST varies on different time scales and these SST variations are often characterized by different features. The TP impact on upstream climate may behave differently when different Atlantic SST variations and thus their feedbacks occur, which deserves further investigations.

Acknowledgements The authors thank Dr. Chao He of the Jinan University for modeling technical assistant and the three anonymous reviewers who provided constructive comments on the earlier version of the manuscript. This study was supported by the National Natural Science Foundation of China (Grants 91637208, 41690123, and 41690120), the "111-Plan" Project of China (Grant B17049), and the Zhuhai Joint Innovative Center for Climate, Environment and Ecosystem, China. M Lu thanks the China Scholarship Council joint $\mathrm{PhD}$ training program for providing support for her stay at the Harvard University. B. Huang is supported by grants from NSF (AGS1338427), NASA (NNX14AM19G), and NOAA (NA14OAR4310160 and NA17OAR4310144). Model experiments were conducted at the supercomputing system Tianhe-2 in Guangzhou, China.

Open Access This article is distributed under the terms of the Creative Commons Attribution 4.0 International License (http://creativeco mmons.org/licenses/by/4.0/), which permits unrestricted use, distribution, and reproduction in any medium, provided you give appropriate credit to the original author(s) and the source, provide a link to the Creative Commons license, and indicate if changes were made.

\section{References}

Carton JA, Huang B (1994) Warm events in the tropical Atlantic. J Phys Oceanogr 24:888-903
Cui YF, Duan AM, Liu YM, Wu GX (2015) Interannual variability of the spring atmospheric heat source over the Tibetan Plateau forced by the North Atlantic SSTA. Clim Dyn 45:1617-1634

Czaja A, Frankignoul C (2002) Observed impact of Atlantic SST anomalies on the North Atlantic Oscillation. J Clim 15:606-623

Czaja A, van der Vaart P, Marshall J (2002) A diagnostic study of the role of remote forcing in tropical Atlantic variability. J Clim 15:3280-3290

Duan AM, Wu GX, Liang XY (2008) Influence of the Tibetan Plateau on the summer climate patterns over Asia in the IAP/ LASG SAMIL model. Adv Atmos Sci 25(4):518-528. https:// doi.org/10.1007/s00376-008-0518-2

Duan AM, Li F, Wang MR, Wu GX (2011) Persistent weakening trend in the spring sensible heat source over the Tibetan Plateau and its impact on the Asian summer monsoon. J Clim 24:5671-5682

Duan AM, Sun RZ, He JH (2017) Impact of surface sensible heating over the Tibetan Plateau on the western Pacific subtropical high: a land-air-sea interaction perspective. Adv Atmos Sci 34:157-168

Feng X, Huang B, Kirtman BP, Kinter JL, Chiu LS (2017) A multimodel analysis of the resolution influence on precipitation climatology in the Gulf Stream region. Clim Dyn 48:1647-1659. https ://doi.org/10.1007/s00382-016-3167-7

Flohn H (1957) Large-scale aspects of the "summer monsoon" in South and East Asia. J Meteorol Soc Jpn 75:180-186

Fontaine B, Janicot S (1996) Sea surface temperature fields associated with West African rainfall anomaly types. J Clim 9:29352940. https://doi.org/10.1175/1520-0442(1996)009,2935:SSTFA W.2.0.CO;2

Hahn DG, Manabe S (1975) The role of mountains in the south Asian monsoon circulation. J Atmos Sci 32(8):1515-1541

Hendon H, Hartmann D (1982) Stationary waves on a sphere: sensitivity to thermal feedback. J Atmos 39:1906-1920

Horel JD, Kousky VE, Kagano MT (1986) Atmospheric conditions in the Atlantic sector during 1983 and 1984. Nature 322:248-251. https://doi.org/10.1038/322248a0

Huang B (2004) Remotely forced variability in the tropical Atlantic Ocean. Clim Dyn 23: https://doi.org/10.1007/s00382-004-0443-8

Huang B, Shukla J (2005) The ocean-atmospheric interactions in the tropical and subtropical Atlantic Ocean. J Clim 18:1652-1672

Huang B, Schope PS, Shukla J (2004) Intrinsic ocean-atmosphere variability of the tropical Atlantic ocean. J Clim 17:2058-2077

Hurrell JW, Visbeck M, Busalacchi A, Clarke RA, Delworth TL, Dickson RR, Johns WE, Koltermann KP, Kushnir Y, Marshall D, Mauritzen C, McCartney MS, Piola A, Reason C, Reverdin G, Schott F, Sutton R, Wainer I, Wright D (2006) Atlantic climate variability and predictability: a CLIVAR perspective. Clim Dyn 19:5100-5121

Hurrell JW et al (2013) The community earth system model: A framework for collaborative research. Bull Amer Meteor Soc 94:1339-1360

Jiang XW, Li YQ, Yang S, Yang K, Chen JW (2016) Interannual variation of summer atmospheric heat source over the Tibetan Plateau and the role of convection around the western Maritime Continent. J Clim 29:121-138. https://doi.org/10.1175/JCLI-D-15-0181.1

Kitoh A (2004) Effects of mountain uplift on East Asian summer climate investigated by a coupled atmosphere-ocean GCM. J Clim 17(4):783-802

Koo CC, Yeh TC (1955) Some calculations of the influence of the large-scale topography on the climate of China. Acta Meteor Sinica 26:167-182 (in Chinese)

Kucharski F, Bracco A, Yoo JH, Tompkins AM, Feudale L, Ruti P, Dell'Aquila A (2009) A Gill-Matsuno-type mechanism explains the tropical Atlantic influence on African and Indian monsoon rainfall. Q J R Meteorol Soc 135:569-579 
Li JP, Ruan CQ (2018) The North Atlantic-Eurasian teleconnection in summer and its effects on Eurasian climates. Environ Res Lett 13:024007

Lindzen RS, Nigam S (1987) On the role of sea surface temperature gradients in forcing low-level winds and convergence in the tropics. J Atmos Sci 44:2418-2436

Liu YM, Bao Q, Duan AM, Qian ZA, Wu GX (2007) Recent progress in the impact of the Tibetan Plateau on climate in China. Adv Atmos Sci 24(6):1060-1076

Liu YM, Wang ZQ, Zhou HF, Wu GX (2017) Two types of summertime heating over Asian large-scale orography and excitation of potential-vorticity forcing II. Sensible heating over Tibetan-Iranian Plateau. Sci China Earth Sci 60(4):733-744. https://doi. org/10.1007/s11430-016-9016-3

Lu RY, Dong BW, Ding H (2006) Impact of the Atlantic multidecadal oscillation on the Asian summer monsoon. Geophys Res Lett 33:L24701. https://doi.org/10.1029/2006GL027655

Lu MM, Yang S, Li ZN, He B, He S, Wang ZQ (2018) Possible effect of the Tibetan Plateau on the "upstream" climate over West Asia, North Africa, South Europe and the North Atlantic. Clim Dyn 51:1485-1498. https://doi.org/10.1007/s00382-017-3966-5

Luo FF, Li SL, Furevik T (2011) The connection between the Atlantic Multidecadal Oscillation and the Indian Summer Monsoon in Bergen Climate Model Version 2.0. J Geophys Res 116:D19117. https://doi.org/10.1029/2011JD015848

Nan SL, Zhao P, Yang S, Chen JM (2009) Springtime tropospheric temperature over the Tibetan Plateau and evolutions of the tropical Pacific SST. J Geophys Res 114:D10104. https://doi. org/10.1029/2008JD011559

Plumb RA (1985) On the three-dimensional propagation of stationary waves. J Atmos Sci 42:217-229

Rajagopalan B, Molnar P (2013) Signatures of Tibetan Plateau heating on Indian summer monsoon rainfall variability. J Geophys Res 118:1-9. https://doi.org/10.1002/jgrd.50124

Rodriguez-Fonseca B et al (2015) Variability and predictability of West African droughts: a review on the role of sea surface temperature anomalies. J Clim 28:4034-4060

Rodwell MJ, Hoskins BJ (1996) Monsoon and the dynamics of deserts. Q J R Meteorol Soc 122:1385-1404

Rodwell MJ, Hoskins BJ (2001) Subtropical anticyclone and summer monsoons. J Clim 14:3192-3211

Sun C, Li JP, Ding RQ, Jin Z (2017) Cold season Africa-Asia multidecadal teleconnection pattern and its relation to the Atlantic multidecadal variability. Clim Dyn 48:3903-3918

Sutton RT, Hodson DLR (2005) Atlantic Ocean forcing of North American and European summer climate. Science 309:115

Vizy EK, Cook KH (2017) Seasonality of the observed amplified Sahara warming trend and implications for Sahel rainfall. J Clim 30:3073-3094

Wagner RG, da Silva AM (1994) Surface conditions associated with anomalous rainfall in the Guinea coastal region. Int J Climatol 14:179-199. https://doi.org/10.1002/joc.3370140205

Wang B, Bao Q, Hoskins B, Wu GX, Liu YM (2008) Tibetan Plateau warming and precipitation changes in East Asia. Geophys Res Lett 35:L14702. https://doi.org/10.1029/2008GL034330

Wang ZQ, Duan AM, Wu GX (2014) Time-lagged impact of spring sensible heat over the Tibetan Plateau on the summer rainfall anomaly in East China: case studies using the WRF model. Clim Dyn 42:2885-2898. https://doi.org/10.1007/s00382-013-1800-2
Wang ZQ, Duan AM, Yang S (2018) Potential regulation on the climatic effect of Tibetan Plateau heating by tropical air-sea coupling in regional models. Clim Dyn doi. https://doi.org/10.1007/ s00382-018-4218-z

Ward MN (1998) Diagnosis and short-lead time prediction of summer rainfall in tropical North Africa at interannual and multidecadal timescales. J Clim 11:3167-3191. https://doi.org/10.1175/15200442(1998)011,3167:DASLTP.2.0.CO;2

Wu GX, Li WP, Guo H (1997) Sensible heat driven air-pump over the Tibetan Plateau and its impacts on the Asian summer monsoon. In: Ye DZ (ed) Collections on the memory of Zhao Jiuzhang. Science Press, Beijing, pp 116-126

Wu GX, Liu YM, Wang TM, Wan RJ, Liu X, Li WP, Wang ZZ, Zhang Q, Duan AM, Liang XY (2007) The influence of mechanical and thermal forcing by the Tibetan Plateau on Asian climate. J Hydrometeorol 8:770-789

Wu GX, Liu Y, Zhu X, Li W, Ren R, Duan A, Liang X (2009) Multiscale forcing and the formation of subtropical desert and monsoon. Ann Geophys 27(9):3631-3644. https://doi.org/10.5194/ angeo-27-3631-2009

Wu GX, Liu YM, He B, Bao Q, Duan AM, Jin FF (2012a) Thermal controls on the Asian summer monsoon. Sci Rep 2:404. https:// doi.org/10.1038/srep00404

Wu ZW, Li JP, Jiang ZH, Ma TT (2012b) Modulation of the Tibetan Plateau snow cover on the ENSO teleconnections: from the East Asian summer monsoon perspective. J Clim 25:2481-2489. https ://doi.org/10.1175/JCLI-D-11-00135.1

Wu GX, Duan AM, Liu YM, Mao JY, Ren RC, Bao Q, He B, Liu BQ, Hu WT (2014) Tibetan Plateau climate dynamics: recent research progress and outlook. Nat Sci Rev. https://doi.org/10.1093/nsr/ nwu045

Xie S-P, Carton JA (2004) Tropical Atlantic variability: patterns, mechanisms, and impacts. In: Wang C, Xie S-P, Carton JA (eds) Earth climate: the ocean-atmosphere interaction. Geophysical Monograph, 147, AGU, Washington D.C, pp 121-142

Yang Y, Xie S-P, Wu L, Kosaka Y, Li J (2017) ENSO forced and local variability of North Tropical Atlantic SST: model simulations and biases. Clim Dyn. https://doi.org/10.1007/s00382-017-3679-9

Ye DZ, Wu GX (1998) The role of the heat source of the Tibetan Plateau in the general circulation. Meteorol Atmos Phys 67:181-198

Yeh TC, Lo SW, Chu PC (1957) The wind structure and heat balance in the lower troposphere over Tibetan Plateau and its surrounding. Acta Meteorol Sin 28:108-121

Zhao P, Yang S, Wu RG, Wen ZP, Chen JM, Wang HJ (2012) Asian origin of interannual variations of summer climate over the extratropical North Atlantic Ocean. J Clim 25:6594-6609. https://doi. org/10.1175/JCLI-D-11-00617.1

Zhao Y, Duan AM, Wu GX (2018) Interannual variability of latespring circulation and diabatic heating over the Tibetan Plateau associated with Indian Ocean forcing. Adv Atmos Sci 35:927-941

Publisher's Note Springer Nature remains neutral with regard to jurisdictional claims in published maps and institutional affiliations. 